\title{
Satisfaction with retention factors in relation to job embeddedness of public school teachers
}

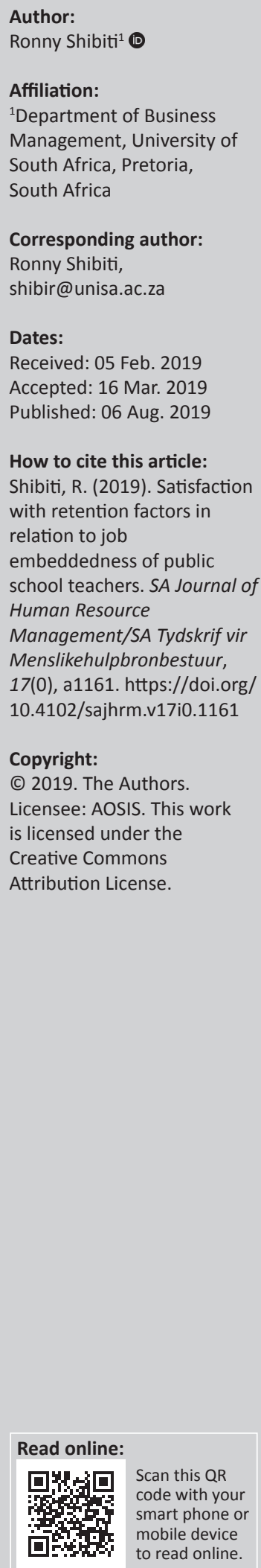

Orientation: The major challenge that organisations face in the contemporary competitive environment is to retain talented and productive employees. To ensure that the education system functions optimally, there is a need for strategic human resource management (HRM) practices to be implemented to assist in retaining qualified and experienced teachers.

Research purpose: The purposes of this study were to establish the relationship between retention factors and job embeddedness, and to establish whether retention factors positively and significantly predict job embeddedness.

Motivation for the study: There is a high turnover among teachers, with many teachers leaving the profession during their early years of teaching. An empirical investigation of the relationship between retention factors and job embeddedness and the outcomes of utilising retention factors and job embeddedness to facilitate the retention of employees is critical.

Research approach/design and method: A non-experimental, quantitative survey was conducted on 278 teachers working in the Tshwane Municipality public schools.

Main findings: A Pearson's correlational analysis revealed positive and significant relationships between retention factors and job embeddedness, while multiple regression analyses revealed that retention factors positively and significantly predict job embeddedness.

Practical/managerial implications: The results from this study afford concrete implications for employers in search of effective employee retention strategies. The main practical contribution of this study is the way in which it demonstrated that retention factors relate to and predict job embeddedness.

Contribution/value-add: This study contributes to the employee retention theory by proposing that employees who are provided with desired retention factors are more likely to be embedded in their jobs and community.

Keywords: retention factors; job embeddedness; compensation; work-life balance; career development; training and development.

\section{Introduction}

\section{Orientation}

The key element that determines the success and survival of any organisation in an extremely competitive global market is the organisation's ability to retain its employees (Alferaih, 2017; Muhoho, 2014; Potgieter \& Ferreira, 2018; Ruvimbo \& Hlanganipai, 2016). Dynamic organisational forces have instigated a need for organisations to understand the processes and outcomes of the employment relationship to increase productivity, advance organisational effectiveness and retain talented employees (Dhanpat, Modau, Lugisani, Mabojane, \& Phiri, 2018; Naidoo, Abarantyne, \& Rugimbana, 2019). No matter the size of the business, and regardless of the industry in which the business operates, organisations are always faced with the challenge of attracting and retaining high-performing employees (Aruna \& Anitha, 2015; Joubert, Nkosi, Steenkamp, \& Molatsane, 2014). When qualified and experienced employees leave an organisation, it may be detrimental to both its performance and its success (Cohen, Cavazotte, Da Costa, \& Ferreira, 2017; Lyria, Namusonge, \& Karanja, 2017).

According to Coetzee and Stoltz (2015), researchers and practitioners are striving to find and develop various organisational practices that are crucial to the retention of employees. Concentrating on employee retention is vital to increase organisational performance and reinforce a country's economy (Cloutier, Felusiak, Hill, \& Pemberton-Jones, 2015). It is vital that 
an organisation recognises and satisfies the needs of its employees to ensure that they remain in the employ of such organisation (Dhanpat et al., 2018), but the organisation should also ensure that the employees' needs are in line with the strategy and operational requirements of the organisation (Pearsall, 2016). When a talented employee resigns from an organisation, the whole cycle of recruitment, training and development has to be repeated, resulting in higher recruitment and training costs (Bhattacharyya, 2017; Lyria et al., 2017), as well as the expense associated with the extreme use of overtime compensation to cope with workforce shortfalls (Lai, 2017).

This study specifically focused on the relationship between retention factors and job embeddedness of teachers in the Tshwane Municipality public schools. There is a high turnover among teachers, with many teachers leaving the profession during their early years of teaching (Mafukata \& Mudau, 2016). Furthermore, too many teachers exit the system and they are not replaced because of the inadequateness of South African college and university systems to address the training and development of teachers (Mafukata \& Mudau, 2016). According to The Centre for Development and Enterprise (2015), many talented graduate teachers opt to move to other countries or find employment in other professions. This results in the loss of thousands of teachers on an annual basis (The Centre for Development and Enterprise, 2015). In addition, more than a quarter of recently qualified teachers end up not teaching in South African schools because of low salaries and the poor image of the teaching profession (The Centre for Development and Enterprise, 2015). A study by Furuta (2015) found that teachers are influenced to stay with their current organisation if they are acknowledged for their contribution and if they know they have contributed to the social context of the school, such as the relationships that they have with learners, colleagues and administrators.

Notwithstanding the various strategic interventions enacted by the Department of Basic Education in South Africa to improve teachers' retention, the department continues to battle with considerably high teacher turnover rates (Mampane, 2012). Furthermore, South Africa is losing the most qualified and experienced teachers in critical subjects such as science, mathematics, language and technology (Mampane, 2012). The motives prompting teachers to leave their employment are vast and intertwined (Mafukata \& Mudau, 2016). It is thus evident that the demand for teachers is high, and it is imperative to retain existing teachers to meet the demand in public schools. Hence, there is a need for strategic human resource management (HRM) practices to be implemented to assist in recruiting and retaining teachers (Ashiedu \& Scott-Ladd, 2010). Accordingly, a profound understanding of the factors that may enhance the retention of teachers in public schools, and thus of the way in which constructs such as retention factors and job embeddedness influence retention, is essential.
A review of the existing literature on retention factors and job embeddedness highlights the following research problems:

- There is a poor understanding of the theoretical and empirical relationship between retention factors and job embeddedness, particularly in South African public schools.

- There is need for an empirical investigation of the relationship between retention factors and job embeddedness and the outcomes of utilising retention factors and job embeddedness to facilitate employee retention.

Considering the previously mentioned research problems, the following general research question has been formulated: Is there a significant relationship between retention factors and job embeddedness of teachers working in the Tshwane Municipality public schools?

\section{Research purposes and objectives}

The purposes of this study were (1) to establish the relationship between retention factors and job embeddedness, and (2) to establish whether retention factors positively and significantly predict job embeddedness.

\section{Literature review}

\section{Retention factors}

Retention factors have an impact on the turnover intentions of employees and should, thus, be considered when formulating strategies to retain employees (Dhanpat et al., 2018; Van Dyk, Coetzee, \& Takawira, 2013). Retention factors are human resource (HR) practices that organisations implement to inspire employees to remain with the organisation and which enhance their performance, for instance, opportunities for career growth, a healthy organisational culture, fair compensation, work-life balance, performance management, supervisor support and independence at work (Coetzee, Oosthuizen, \& Stoltz, 2016; Kumar \& Santhosh, 2014; Van Dyk et al., 2013). Kumar and Santhosh (2014) described retention factors as HR practices that are enacted to encourage employees to remain with the organisation, for example, fair compensation, opportunities for career growth, work-life balance, a healthy organisational culture, performance management, supervisor support and independence at work.

It is the responsibility of management to implement interventions such as creating a positive working relationship between managers and employees, paying employees for performing their jobs well and maintaining a healthy and safe work environment to prevent employees from leaving the organisation (Tourangeau, Patterson, Saari, Thomson, \& Cranley, 2017). Work-life balance, compensation, opportunities for career growth and development, the opportunity to use one's skills and knowledge in the company, and challenging work are cited as some of the most important retention factors for 
employees (Coetzee \& Stoltz, 2015; Davidescu \& Issa Eid, 2017; Kumar \& Santhosh, 2014; Lyria et al., 2017; Mohammad, 2015; Roy, 2015). Compensation, job characteristics, training and development, career opportunities, talent management, supervisor support and work flexibility are the most important retention factors in the South African context (Dhanpat et al., 2018; Döckel, 2003; Van Dyk \& Coetzee, 2012).

Mohammad (2015) posits that employee involvement, providing trust-based inspirational leadership, fair compensation, orientations, health and safety programmes, training programmes, fair rewards or incentives, developing grievance-handling mechanisms, flexibility in working hours, coaching, mentoring and maintaining positive relationships between employees all enhance employee retention in an organisation. It is essential that organisations offer their employees the best working environment, career growth opportunities, rewards, work-life balance and supervisor support because this will inspire the employees to give their best to the organisation (Roy, 2015). Pek-Greer and Wallace (2017) maintain that factors such as employee benefits, employee remuneration, professional development opportunities and work environment substantially influence employee retention. Thus, a lack of these HR interventions in an organisation may lead to employee turnover (Cohen et al., 2017).

\section{Job embeddedness}

According to Dechawatanapaisal (2018), a problem that continuously challenges researchers and practitioners is to find the reasons that make people stay with their organisations. In their classic study, Mitchell and Lee (2001) developed a job embeddedness model to help researchers and HR practitioners to understand the reasons why people stay with their organisations (Ampofo, Coetzer, \& Poisat, 2017; Coetzer, Redmond, \& Barrett, 2014; Hopson, Petri, \& Kufera, 2018; Kiazad, Hom, Holtom, \& Newman, 2015; Thakur \& Bhatnagar, 2017). The concept of job embeddedness was then defined as a mesh in which an individual may be trapped - an employee who is highly embedded has many closely linked relationships in the workplace (Chena \& Shafferb, 2017; Coetzer, Inma, Poisat, Redmond, \& Standing, 2018; Hopson et al., 2018; Marasi, Cox, \& Bennett, 2016; Mitchell \& Lee, 2001; Sanders, 2015). Links, fit and sacrifice were then identified as the three components of job embeddedness (Ampofo et al., 2017; Ma, Mayfield, \& Mayfield, 2018; Mitchell, Holtom, Lee, Sablynski, \& Erez, 2001; Mitchell \& Lee, 2001). Links refer to the level to which people are connected to others inside and outside the organisation (Ampofo et al., 2017; Ma et al., 2018). Fit relates to the manner in which people's jobs and communities are comparable to the other characteristics of their lives (Ma et al., 2018; Mitchell et al., 2001; Mitchell \& Lee, 2001). Sacrifice refers to the simplicity with which relations may be dissolved - what they would surrender if they move, especially if they are forced to relocate to other places (Ampofo et al., 2017; Ma et al., 2018; Mitchell \& Lee, 2001).
Job embeddedness encapsulates a wide range of influences on employee retention, specifically with regard to clarifying the reasons why employees decide to remain with their current employer (Coetzer et al., 2018; Coetzer, Inma, Poisat, Redmond, \& Standing, 2019; Peltokorpi, Allen, \& Froese, 2015). This embeddedness may stem from within the job context (organisation), as well as from outside the employee's immediate work environment (community) (Ampofo et al., 2017; Coetzer et al., 2018, 2019; Kale, 2014; Potgieter \& Ferreira, 2018). Job embeddedness, thus, considers job satisfaction while combining the conceptions of work environment and community (Hopson et al., 2018). The concept of job embeddedness tries to broaden the scope of factors that may clarify the reasons why employees remain in jobs by adding aspects that are non-affective (structural links to other people), and by considering off-the-job factors (fit in the community) as contributoryaspectsofemployeeretention(Dechawatanapaisal, 2018). This perspective is different from traditional turnover models, which are more concerned with the motives why employees might leave their jobs (Hopson et al., 2018). Bambacas and Kulik (2013) maintain that job embeddedness focuses on the degree of networks that an individual encounters through his or her work experiences, roles, relationships and responsibilities. When these interconnections become more multifaceted, an individual will become more embedded within the organisation and would be less likely to leave the organisation (Bambacas \& Kulik, 2013).

According to Ma et al. (2018), it appears that a person with high job embeddedness is less likely to resign compared with a person with low job embeddedness, and job embeddedness fosters retention more than job satisfaction and organisational commitment combined. Job embeddedness is deemed superior because of its focus on the contextual forces that influence retention rather than affect or affect-saturated constructs such as satisfaction, commitment and involvement (Lee, Burch, \& Mitchell, 2014; Mitchell et al., 2001). Various studies have revealed that job embeddedness significantly improves the prediction of subsequent turnover even after controlling for commitment, satisfaction and gender, and also that job embeddedness goes beyond a combination of measures of ease of movement and perceived desirability (Crossley, Bennett, Jex, \& Burnfield, 2007; Mitchell et al., 2001; Mitchell \& Lee, 2001). Nevertheless, researchers still have much to explore about the holistic potential of job embeddedness as an important variable in the retention of employees (Dechawatanapaisal, 2018).

This study aims to extend existing job embeddedness research by investigating retention factors that are related to and predict job embeddedness. Mitchell et al. (2001) recommended that organisations should revise their HR practices to nurture employees' job embeddedness because effective practices can generate an environment that inspires employees to be more satisfied and embedded, thus minimising turnover. It is important to note that the construct of job embeddedness does not replace the usefulness of other constructs such as organisational 
commitment, job involvement and job satisfaction in understanding imminent turnover, although it does present a potent instrument for exploring employee turnover (Lee et al., 2014; Mitchell \& Lee, 2001). Crossley et al. (2007) also established that job embeddedness acts together with job satisfaction to predict voluntary turnover, thus signifying that the job embeddedness construct extends further than the unfolding model of turnover.

\section{Methods}

\section{Participants and setting}

The study was a non-experimental, cross-sectional quantitative survey, with a convenience sample of 708 teachers working in the Tshwane Municipality public schools. Two hundred and seventy-eight usable questionnaires were received. The data were collected between February and March 2017.

\section{Measuring instruments}

Retention factors were measured using the Retention Factors Measuring Scale (RFMS; Döckel, 2003). The RFMS includes items that measure employees' satisfaction with compensation, job characteristics, training and development opportunities, supervisor support, career opportunities and work-life policies (Coetzee \& Stoltz, 2015; Döckel, Basson, \& Coetzee, 2006). The reliability of the scale was found to be as follows: compensation (0.90), job characteristics (0.41), training and development (0.83), supervisory support (0.90), career opportunities (0.76) and work-life policies (0.87) (Döckel et al., 2006). The overall instrument achieved a reliability coefficient of 0.93 (Shibiti, 2017, p. 81). This instrument is thus proven as valid and reliable in this context.

Job embeddedness was measured using the Job Embeddedness Scale (JES; Mitchell et al., 2001). The JES is a self-rating instrument, and consists of 37 items covering all three dimensions of the construct of job embeddedness, namely, fit, links and sacrifice, for both the community and organisation. Mitchell and Lee (2001) found that the reliability for the overall job embeddedness was 0.85 . In the present study, the reliability for the JES was 0.91 .

\section{Research procedure}

The results for this article were extracted from the master's study that was conducted at University of South Africa (UNISA) (Shibiti, 2017). Questionnaires were distributed to teachers with envelopes and a covering letter stating the contact details of the researchers, the purpose of the study and ethical standards that it upholds. The confidentiality of participants was protected during the process of collecting, analysing and interpreting the data.

\section{Statistical analysis}

The data were analysed using the Statistical Package for Social Sciences (SPSS), version 23 (2015). The correlations between retention factors and job embeddedness were calculated using the Pearson's product moment correlations. Multiple regression analysis was conducted to examine whether retention factors (independent) predict job embeddedness (dependent). The confidence interval level was set at $95 \%(p \leq 0.05)$ and the practical effect size was set at $r \geq 0.30 \geq 0.50$ (medium-to-large effect) to determine the statistical significance and counter the probability of type 1 errors (Mitonga-Monga \& Cilliers, 2015; Tredoux \& Durrheim, 2013). The $f^{2}$ effect sizes were calculated to investigate the practical significance of the $\Delta R^{2}$ values.

\section{Ethical considerations}

Permission has been obtained from the Human Resource Management Research, Ethics and Innovation Committee at UNISA (reference number: 2016_HRM_012) and the Department of Basic Education (Gauteng: Department of Education and Tshwane North District).

\section{Results \\ Descriptive statistics}

This section addresses the means, standard deviations and the internal consistency (reliability) of the measuring instruments, indicated by Cronbach's alpha coefficient $(r)$. Table 1 indicates the means, standard deviations and Cronbach's alpha for the retention factors and job embeddedness variables. The mean and standard deviation for the overall retention factors were $M=3.08$ and $S D=0.51$, respectively. This indicated that the participants were moderately satisfied with the retention factors that are provided by their organisation. The overall job embeddedness mean and standard deviation were $M=3.33$ and $S D=0.56$, respectively, showing that the participants were moderately embedded in their work. The results showed that both the RFMS and JES were reliable (well above $r^{3} 0.60$ ).

\section{Correlations analysis}

The correlations between retention factors and job embeddedness were calculated by computing the Pearson's product moment correlations. To determine the statistical

TABLE 1: Descriptive statistics for retention factors and job embeddedness.

\begin{tabular}{lccc}
\hline Variables & Mean & Standard deviations & Cronbach's alpha \\
\hline RFMS & 3.08 & 0.51 & 0.91 \\
Compensation & 2.95 & 0.91 & 0.97 \\
Job characteristics & 3.15 & 0.53 & 0.48 \\
Training and development & 3.43 & 0.84 & 0.90 \\
Supervisor support & 2.95 & 0.55 & 0.50 \\
Career development & 3.19 & 0.65 & 0.65 \\
Work-life balance & 2.91 & 1.00 & 0.88 \\
JES & 3.33 & 0.56 & 0.91 \\
Link-community & 3.56 & 0.89 & 0.88 \\
Link - organisation & 3.87 & 0.73 & 0.93 \\
Fit - community & 1.63 & 0.45 & 0.32 \\
Fit - organisation & 1.81 & 0.74 & 0.61 \\
Sacrifice - community & 3.61 & 0.78 & 0.60 \\
Sacrifice - organisation & 3.40 & 0.79 & 0.91 \\
\hline
\end{tabular}

RFMS, Retention Factors Measuring Scale; JES, Job Embeddedness Scale. 
significance, the confidence interval level was set at 95\% ( $p \leq$ $0.05)$ and the cut-off practical effect size was $r \geq 0.30 \geq 0.50$ (medium-to-large effect) (Tredoux \& Durrheim, 2013). Table 2 illustrates the Pearson's product moment correlations between RFMS and JES.

Table 2 demonstrates that retention factors significantly and positively correlate with job embeddedness $(r=0.60$; large effect; $p \leq 0.05)$. The retention factors also correlate with the six sub-components of job embeddedness. The results indicated that, overall, retention factors correlated significantly with fit - community $(r=0.32$; medium effect; $p \leq 0.05)$, fit - organisation $(r=0.47$; medium effect; $p \leq 0.05)$, links - organisation ( $r=0.13$; small effect; $p \leq 0.05)$, sacrifice community ( $r=0.42$; medium effect; $p \leq 0.05)$ and sacrifice organisation $(r=0.68$; large effect; $p \leq 0.05)$.

\section{Multiple regressions analysis}

Table 3 illustrates the results of the multiple regression analyses that were conducted to establish whether retention factors acted as a predictor of job embeddedness.

Seven regression models were deduced - one model for job embeddedness (JES) and a further six for the sub-components of job embeddedness. All the models were found to be statistically significant $F(p \leq 0.05)$ except for models 4 (links community) and 5 (links - organisation), which were found not to be statistically significant. The models accounted for $41 \%\left(R^{2}=0.41\right.$ : overall job embeddedness $) ; 11 \%\left(R^{2}=0.11\right.$ : fit - community); $30 \%\left(R^{2}=0.30\right.$ : fit - organisation $) ; 17 \%\left(R^{2}=\right.$ 0.17: sacrifice -community) and 53\% $\left(R^{2}=0.53\right.$ : sacrifice organisation) of the variance in the job embeddedness variables.

In model 1 (JES), compensation $(\beta=0.36 ; p=0.00)$, training and development $(\beta=0.28 ; p=0.00)$ and career development ( $\beta=0.15 ; p=0.02)$ acted as significant positive predictors of the overall job embeddedness. In model 2 (fit - community), compensation $(\beta=0.18 ; p=0.01)$ and training and development $(\beta=0.18 ; p=0.02)$ acted as significant positive predictors of fit - community. In model 3 (fit - organisation), compensation $(\beta=0.17 ; p=0.01)$ and training and development $(\beta=0.45 ; p=0.00)$ acted as significant positive predictors of fit - organisation. In model 6 (sacrifice community), compensation $(\beta=0.31 ; p=0.00)$ acted as the only significant and positive predictor of sacrifice community. In model 7 (sacrifice -organisation), compensation $(\beta=0.49 ; p=0.00)$, training and development $(\beta=0.26 ; p=0.00)$ and career development $(\beta=0.15 ; p=0.01)$ acted as significant positive predictors of sacrifice organisation.

\section{Discussion \\ Outline of the results}

The employee retention and behaviour profile revealed that, overall, the participants were moderately satisfied with the training and development opportunities with which they

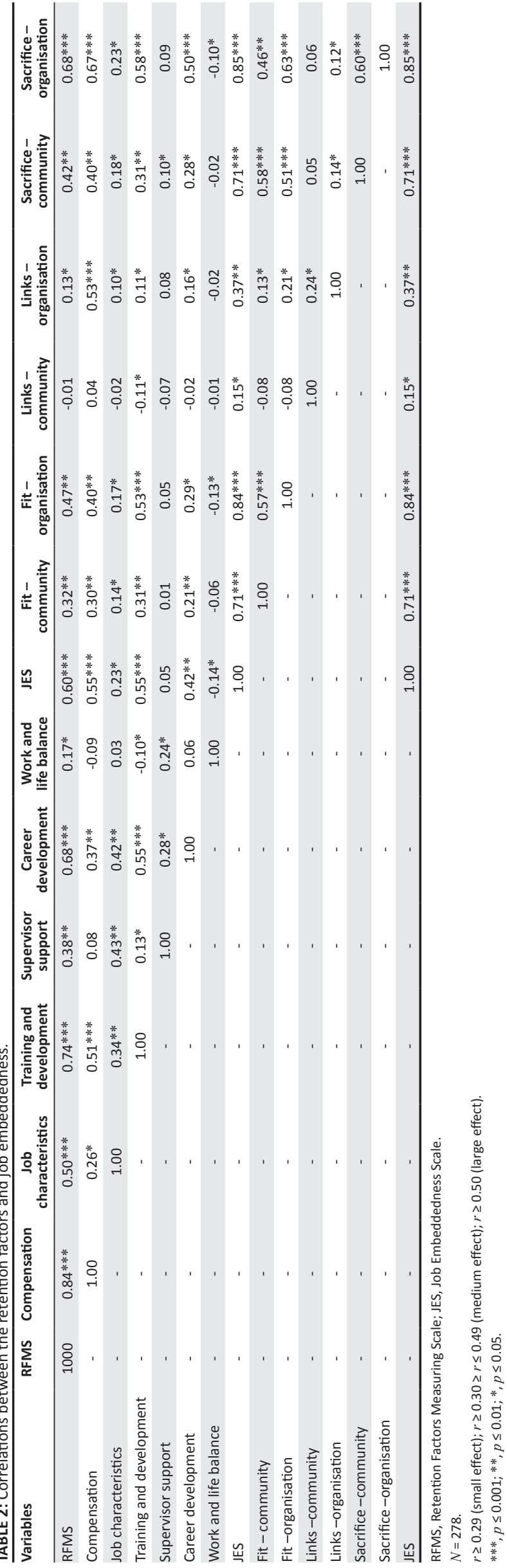


TABLE 3a: Multiple regression analysis: Retention factors as a predictor of job embeddedness

\begin{tabular}{|c|c|c|c|c|c|c|c|c|c|c|c|c|}
\hline \multirow[t]{2}{*}{ Variable } & \multicolumn{3}{|c|}{$\begin{array}{l}\text { Model } 1 \\
\text { JES }\end{array}$} & \multicolumn{3}{|c|}{$\begin{array}{c}\text { Model } 2 \\
\text { Fit - community }\end{array}$} & \multicolumn{3}{|c|}{$\begin{array}{c}\text { Model } 3 \\
\text { Fit - organisation }\end{array}$} & \multicolumn{3}{|c|}{$\begin{array}{c}\text { Model } 4 \\
\text { Links - community }\end{array}$} \\
\hline & $B$ & $\beta$ & $p$ & $B$ & $\beta$ & $p$ & $B$ & $\beta$ & $p$ & $B$ & $\beta$ & $p$ \\
\hline (Constant) & 65.52 & - & - & 11.06 & - & - & 21.31 & - & - & 10.47 & - & - \\
\hline Compensation & 0.55 & $0.36 * * *$ & 0.00 & 0.07 & $0.18 * *$ & 0.01 & 0.10 & $0.17 * *$ & 0.01 & 0.02 & 0.11 & 0.11 \\
\hline Job characteristics & 0.04 & 0.00 & 0.94 & 0.09 & 0.04 & 0.56 & -0.05 & -0.02 & 0.78 & 0.02 & 0.02 & 0.77 \\
\hline Training and development & 1.01 & $0.28 * * *$ & 0.00 & 0.16 & $0.18^{*}$ & 0.02 & 0.58 & $0.45 * * *$ & 0.00 & -0.09 & $-0.20 * *$ & 0.02 \\
\hline Supervisor support & -0.20 & -0.04 & 0.48 & -0.07 & -0.05 & 0.43 & 0.01 & 0.00 & 0.96 & -0.05 & -0.08 & 0.25 \\
\hline Career development & 0.71 & $0.15 *$ & 0.02 & 0.05 & 0.04 & 0.56 & -0.02 & -0.01 & 0.86 & 0.04 & 0.07 & 0.38 \\
\hline Work and life balance & -0.31 & -0.07 & 0.17 & -0.02 & -0.01 & 0.82 & -0.11 & -0.06 & 0.22 & 0.00 & 0.00 & 0.98 \\
\hline
\end{tabular}

$N=278$.

$\beta$, standardised regression coefficient; $B$, unstandardised regression coefficient; JES, Job Embeddedness Scale.

${ }^{+} R^{2} \leq 0.12$ (small practical effect size); ${ }^{++} R^{2} \geq 0.13 \leq 0.25$ (medium practical effect size); ${ }^{++} R^{2} \geq 0.26$ (large practical effect size).

$R$ = Model 1 - JES: 0.65; Model 2 - Fit - community: 0.36; Model 3 - Fit - organisation: 0.60; Model 4 - Links - community: 0.17.

Adjusted $R^{2}=$ Model 1 - JES: $0.41^{+++}$; Model 2 - Fit - community: 0.11+; Model 3 - Fit - organisation: $0.30^{+++}$; Model 4 - Links - community: 0.01

$F(d f ;$ mean square $)=$ Model $1-$ JES: $6 ; 6317.27)=31.71 * * * ;$ Model $2-$ Fit - community: $(6 ; 116.11)=6.48 * * *$ Model $3-$ Fit - organisation: $(6 ; 615.43)=20.35 * * *$ Model $4-$ Links - community: $(6 ; 7.61)=1.31$.

***, $(p \leq 0.001) ; * *,(p \leq 0.01) ; *,(p \leq 0.05)$

TABLE 3b: Multiple regression analysis: Retention factors as a predictor of job embeddedness

\begin{tabular}{|c|c|c|c|c|c|c|c|c|c|}
\hline \multirow[t]{2}{*}{ Variable } & \multicolumn{3}{|c|}{$\begin{array}{c}\text { Model } 5 \\
\text { Links - organisation }\end{array}$} & \multicolumn{3}{|c|}{$\begin{array}{c}\text { Model } 6 \\
\text { Sacrifice - community }\end{array}$} & \multicolumn{3}{|c|}{$\begin{array}{c}\text { Model } 7 \\
\text { Sacrifice - organisation }\end{array}$} \\
\hline & $\boldsymbol{B}$ & $\beta$ & $p$ & $B$ & $\beta$ & $p$ & $\boldsymbol{B}$ & $\beta$ & $p$ \\
\hline (Constant) & 4.52 & - & - & 5.87 & - & - & 10.37 & - & - \\
\hline Job characteristics & 0.04 & 0.03 & 0.73 & 0.02 & 0.02 & 0.74 & -0.15 & -0.04 & 0.42 \\
\hline Training and development & 0.02 & 0.04 & 0.67 & 0.04 & 0.09 & 0.23 & 0.40 & $0.26 * * *$ & 0.00 \\
\hline Supervisor support & 0.03 & 0.03 & 0.63 & 0.02 & 0.03 & 0.69 & -0.01 & -0.00 & 0.94 \\
\hline Work and life balance & -0.02 & -0.03 & 0.62 & 0.01 & 0.01 & 0.87 & -0.07 & -0.04 & 0.39 \\
\hline
\end{tabular}

$N=278$.

$\beta$, standardised regression coefficient; $B$, unstandardised regression coefficient.

${ }^{+} R^{2} \leq 0.12$ (small practical effect size); ${ }^{+{ }^{+}} R^{2} \geq 0.13 \leq 0.25$ (medium practical effect size); ${ }^{+++} R^{2} \geq 0.26$ (large practical effect size)

$R=$ Model $5-$ Links - organisation: 0.17; Model 6 - Sacrifice - community: 0.43; Model $7-$ Sacrafice - organisation: 0.73 .

Adjusted $R^{2}=$ Model 5 - Links - organisation: 0.01; Model 6- Sacrifice - community: 0.1 $1^{+++}$; Model 7 - Sacrafice - organisation: $0.53^{+++}$

$F(d f ;$ mean square $)=$ Model $5-$ Links - organisation: $6 ; 11.81)=1.35$; Model $6-$ Sacrifice - community: $(6 ; 46.64)=10.16 * * * ;$ Model $7-$ Sacrafice - organisation: $(6 ; 1538.48)=52.58 * * *$

JES, Job Embeddedness Scale; $\beta$, standardised regression coefficient; $B$, unstandardised regression coefficient.

$* * *,(p \leq 0.001) ; * *,(p \leq 0.01) ; *,(p \leq 0.05)$.

were provided. Concerning compensation, job characteristics, supervisor support, career development and work-life balance, the participants were between neutral and satisfied. They also recorded moderate levels of job embeddedness, although they perceived that they did not fit with the community and organisation as indicated by low mean scores in Table 1.

The correlations results suggested that retention factors significantly and positively correlate with job embeddedness. This implies that the participants who were more satisfied with the retention factors are more embedded in their jobs as opposed to the other participants. The findings resemble Dechawatanapaisal's (2018) conclusion that a favourable HR approach as perceived by employees inspires them to develop a sense of embeddedness within their organisation. The participants who indicated greater satisfaction with compensation seemed to perceive that they had a high level of the overall job embeddedness; they fitted with both the community and organisation; they had links to the organisation and they would experience considerable organisational sacrifice if they were to leave their jobs. Performance appraisal and rewards also embed employees in the organisation by improving their perceptions of fit to the organisation (Bambacas \& Kulik, 2013).
The results also suggest that training and development correlated positively with job embeddedness. This indicates that the participants who perceived that their organisation provided them with opportunities for training and development improved the links they had in the organisation and it led them to feel that they would sacrifice much if they were to leave the organisation. The participants seemed to be satisfied with their career development opportunities, which made them feel like they would sacrifice much if they were to leave the organisation. This is in line with research findings that managers should intensify the perceived costs of leaving an organisation by providing training and implementing career development programmes for their employees (Bambacas \& Kulik, 2013; Ferreira, Martinez, Lamelas, \& Rodrigues, 2017; Van Dyk et al., 2013).

The multiple regression results revealed that retention factors predict job embeddedness with compensation, training and development, and career development contributing the most to explaining the variance in job embeddedness. The findings were consistent with previous studies, which found that job embeddedness is significantly predicted by retention factors such as job characteristics, career opportunities, training and development, and supervisor support (Bambacas \& Kulik, 2013; Coetzee, Schreuder, \& Tladinyane, 2014; 
Van Dyk et al., 2013). This implies that satisfaction with compensation, training and development, and career development opportunities are associated with high levels of job embeddedness. The results also revealed that satisfaction with compensation correlated with fit and sacrifice in respect of both on-the-job and off-the-job environments. This may be explained by the fact that employees who are satisfied with the rewards system in the organisation are more likely to perceive that they fit with the organisation while they are also able to afford engaging in extramural activities in the community. Ultimately, it would appear that these employees conclude that the cost of leaving their current organisation and community would be very high (Shibiti, 2017).

Satisfaction with training and development was found to be related to a high level of fit (both on the job and off the job) and sacrifice in respect of the organisation. This implied that employees who are happy with the developmental initiatives implemented by their organisation are more likely to perceive that the skills they gain from those initiatives are helpful in cementing their place in the organisation and in taking on extra roles outside of work. Ultimately, those employees tend to stay with their organisation and community because, if they leave, they would forfeit training opportunities (Shibiti, 2017). The findings are consistent with Van Dyk et al.'s (2013) conclusions that satisfaction with training and development opportunities best predicts organisational fit, and satisfaction with career development opportunities is associated with a high level of sacrifice if the employee were to leave the organisation. Bambacas and Kulik (2013) and Van Dyk et al. (2013) also found that satisfaction with career opportunities in the organisation best predicts organisational sacrifice. This implies that if organisations provide their employees with career development opportunities such as recruiting internally for high positions, job expansion and enrichment, employees will perceive that they would sacrifice a lot if they were to resign from the organisation (Shibiti, 2017). This then motivates the employees to remain with the organisation to benefit from the career development opportunities offered by the organisation.

\section{Limitations of the study}

The results were limited in respect of generalising the findings and making recommendations because of a number of factors such as sample size, characteristics of the sample and the psychometric properties of the RFMS and JES. The following limitations of the empirical study should be considered when interpreting the results:

- The study was limited to 278 teachers working in public schools in Tshwane Municipality. Convenience sampling was used to select the participants and, therefore, it is not possible to generalise the results of this study to all population and other occupational contexts. If they are to be representative or resemble the total workforce, quantitative studies similar to this study should be conducted with more participants, bearing in mind the large number of public school teachers in question.
- In view of the fact that the study was cross-sectional in nature, it was not possible to draw inferences about causation because the correlations between the two constructs were interpreted rather than established.

- The RFMS (Döckel, 2003) and JES (Mitchell \& Lee, 2001) were dependent on the participants' self-awareness and personal perceptions, which may be both subjective and biased.

Notwithstanding these limitations, the findings of this study provided new knowledge on the relationship between retention factors and job embeddedness as it applies to the public school context in South Africa.

\section{Practical implications and recommendations}

The results from this study afford concrete implications for employers in search of effective employee retention strategies. The main practical contribution of this study was the way in which it demonstrated that retention factors correlate with and predict job embeddedness. The findings confirmed the need to consider retention factors in the public school context to understand the job embeddedness of public school teachers.

Organisations should provide their employees with improved compensation, training and development, and career development opportunities as this may lead to high level of fit to both the community and organisation, improve the links that employees have in the organisation and increase the perceived organisational sacrifice that employees would incur if they were to leave their jobs. Accordingly, organisations should ensure that their employees are satisfied with their compensation, training and development, and career development opportunities. Organisations may assist employees to fit into their jobs and the organisation by providing supervisory support (offering assistance, guidelines, trust in and praise for subordinates) and by empowering them to create stronger links with their co-workers (Takawira, Coetzee, \& Schreuder, 2014).

\section{Future studies}

The findings of this study highlighted the need for further research into the relationship between retention factors and job embeddedness. It is also strongly recommended that future research should take into consideration the limitations of this study. The study was limited to 26 public schools and 278 teachers in the Tshwane North District, and thus future research should use a randomised sampling process with larger samples and include different occupational fields, races, genders and ages.

This study was cross-sectional in nature, and it was, therefore, not possible to establish causal relationships between the variables under investigation. Consequently, longitudinal studies are recommended to determine the influence of the variables that were tested in this study on 
retention and performance practices within organisations. Test-retest reliability may also be calculated to determine the reliability of all the items of the measuring instruments that were used.

Future studies should apply diverse methodologies, both qualitative and quantitative, which would result in a broader understanding of the relationship between retention factors and job embeddedness. Demographic profile should also be used as moderator variable in an investigation into the relationships between retention factors and job embeddedness.

\section{Conclusions}

The following overall conclusions were drawn:

- Satisfaction with retention factors plays an important role in explaining employees' level of job embeddedness. Individuals who are satisfied with the compensation, training and development, and career development opportunities are more likely to be embedded in their job.

- Individuals who are satisfied with compensation tend to demonstrate high levels of fit and sacrifice in respect of both on-the-job and off-the-job environments.

- Satisfaction with training and development leads to high levels of fit (both on the job and off the job) and sacrifice - organisation.

- Individuals who are satisfied with their career development opportunities tend to demonstrate a high level of organisational sacrifice.

The empirical statistical relationships that were found between retention factors and job embeddedness provided new understanding in respect of the retention of employees in an organisation. The correlational analyses revealed that employees who are satisfied with retention factors are also likely to be embedded in their work. This suggests strongly that retention factors should be considered in the development of a behavioural model for both retention and performance practices.

\section{Acknowledgements}

The author would like to express his sincere thanks and deepest gratitude to his MCom supervisors, Dr MitongaMonga Jeremy and Mrs Lerotholi Mpho, for providing guidance and sharing their knowledge and expertise with him during the MCom study.

\section{Competing interests}

The author declares that he has no financial or personal relationships that may have inappropriately influenced him in writing this article.

\section{Authors' contributions}

This article is solely the work of the author.

\section{Funding information}

The Directorate of Student Funding and the Graduate Development Fellowship programme at UNISA funded the author to conduct this study.

\section{Data availability statement}

Data sharing is not applicable to this article as no new data were created or analysed in this study.

\section{Disclaimer}

The views and opinions expressed in this article are those of the author and do not necessarily reflect the official policy or position of any affiliated agency of the author.

\section{References}

Alferaih, A. (2017). Developing a conceptual model to measure talent's turnove intention in tourism organisations of Saudi Arabia. International Journal of Organizational Analysis, 25(1), 2-23. https://doi.org/10.1108/IJOA-10-20140803

Ampofo, E. T., Coetzer, A., \& Poisat, P. (2017). Relationships between job embeddedness and employees' life satisfaction. Employee Relations, 39(7), 951-966. https://doi org/10.1108/ER-10-2016-0199

Aruna, M., \& Anitha, J. (2015). Employee retention enablers: Generation Y employees. SCMS Journal of Indian Management, 12(3), 94-104.

Ashiedu, J., \& Scott-Ladd, B. (2010). Improving worth to reduce teacher shortages: The role of strategic human resource management. International Journal of Employment Studies, 18(2), 1-36.

Bambacas, M., \& Kulik, C. T. (2013). Job embeddedness in China: How HR practices impact turnover intentions. The International Journal of Human Resource Management, 24(10), 1933-1952. https://doi.org/10.1080/09585192.2012.725 074

Bhattacharyya, D. K. (2017). Book review: The magnetic organisation - Attracting and retaining the best talent. Business Perspectives and Research, 5(1), 110-112. https://doi.org/10.1177/2278533716671633

Chena, Y., \& Shafferb, M. A. (2017). The influences of perceived organizational support and motivation on self-initiated expatriates' organizational and community embeddedness. Journal of World Business, 52(2), 197-208. https://doi. org/10.1016/j.jwb.2016.12.001

Cloutier, O., Felusiak, L., Hill, C., \& Pemberton-Jones, E. J. (2015). The importance of developing strategies for employee retention. Journal of Leadership, Accountability and Ethics, 12(2), 119-130.

Coetzee, M., Oosthuizen, R. M., \& Stoltz, E. (2016). Psychosocial employability attributes as predictors of staff satisfaction with retention factors. South African Journal of Psychology, 46(2), 232-243. https://doi.org/10.1177/0081246315595971

Coetzee, M., Schreuder, D., \& Tladinyane, R. (2014). Employees' work engagement and job commitment: The moderating role of career anchors. SA Journal of Human Resource Management, 12(1), 1-12. https://doi.org/10.4102/sajhrm. v12i1.572

Coetzee, M., \& Stoltz, E. (2015). Employees' satisfaction with retention factors: Exploring the role of career adaptability. Journal of Vocational Behavior, 89(2015), 83-91. https://doi.org/10.1016/j.jvb.2015.04.012

Coetzer, A., Inma, C., Poisat, P., Redmond, J., \& Standing, C. (2018). Job embeddedness and employee enactment of innovation-related work behaviours. International Journal of Manpower, 39(2), 222-239. https://doi.org/10.1108/IJM-04-20160095

Coetzer, A., Inma, C., Poisat, P., Redmond, J., \& Standing, C. (2019). Does job embeddedness predict turnover intentions in SMEs? International Journal of Productivity and Performance Management, 68(2), 340-361. https://doi. org/10.1108/IJPPM-03-2018-0108

Coetzer, A., Redmond, J., \& Barrett, R. (2014). Job embeddedness and the importance of retaining small firm employees. In Proceedings of the 28th Australian and New Zealand Academy of Management Conference: Reshaping management for impact, 13 December 2013 (pp. 1-20). Sydney: ANZAM.

Cohen, M., Cavazotte, F. C. N., Da Costa, T. M., \& Ferreira, K. C. S. (2017). Corporate social-environmental responsibility as an attraction and retention factor for young professionals. Brazilian Business Review, 14(1), 21-41. https://doi.org/10.15728/ bbr.2017.14.1.2

Crossley, C. D., Bennett, R. J., Jex, S. M., \& Burnfield, J. L. (2007). Development of a global measure of job embeddedness and integration into a traditional model of voluntary turnover. Journal of Applied Psychology, 92(4), 1031-1042. https://doi. org/10.1037/0021-9010.92.4.1031

Davidescu, A. A., \& Issa Eid, T. M. (2017). Identifying the main determinants of retention in Jordanian hospitals. An empirical analysis based on Mccloskey/ Mueller satisfaction scale. Ecoforum, 6(1). 
Dechawatanapaisal, D. (2018). Examining the relationships between HR practices, organizational job embeddedness, job satisfaction, and quit intention: Evidence from Thai accountants. Asia-Pacific Journal of Business Administration, 10(2/3), from Thai accountants. Asia-Pacific Journal of Business

Dhanpat, N., Modau, F. D., Lugisani, P., Mabojane, R., \& Phiri, M. (2018). Exploring employee retention and intention to leave within a call centre. SA Journal of Human Resource Management, 16(0), a905. https://doi.org/10.4102/sajhrm.v16i0.905

Döckel, A. (2003). The effect of retention factors on organisational commitment: An investigation of high technology employees (Unpublished master's dissertation). Pretoria: University of Pretoria.

Döckel, A., Basson, J., \& Coetzee, M. (2006). The effect of retention factors on organisational commitment: An investigation of high technology employees. SA Journal of Human Resource Management, 4(2), 20-28. https://doi.org/10.4102/sajhrm.v4i2.91

Ferreira, A. I., Martinez, L. M., Lamelas, J. P., \& Rodrigues, R. I. (2017). Mediation of job embeddedness and satisfaction in the relationship between task characteristics and turnover: A multilevel study in Portuguese hotels. International Journal of Contemporary Hospitality Management, 29(1), 248-267. https://doi. org/10.1108/IJCHM-03-2015-0126

Furuta, S. H. (2015). A case study of teacher retention in three Title I Hawaii schools (Published doctoral thesis). Ann Arbor, MI: ProQuest.

Hopson, M., Petri, L., \& Kufera, J. (2018). A new perspective on nursing retention Job embeddedness in acute care nurses. Journal for Nurses in Professional Development, 34(1), 31-37. https://doi.org/10.1097/NND.0000000000000420

Joubert, M., Nkosi, P., Steenkamp, E., \& Molatsane, W. (2014). Introduction to human resource management: A practical guide. Pretoria: Frontline Books.

Kale, M. D. (2014).Correlational study of job embeddedness measures and employee turnover in selected BPO companies in India (Unpublished doctoral thesis). Minneapolis, MN: Capella University.

Kiazad, K., Hom, P. W., Holtom, B. C., \& Newman, A. (2015). Job embeddedness: A multifoci theoretical extension. Journal of Applied Psychology, 100(3), 641-659. https://doi.org/10.1037/a0038919

Kumar, G. S., \& Santhosh, C. (2014). Factor analysis approach to explore dimensions of employee retention in BPO industry in Kerala. Journal of Social Welfare and Management, 6(2), 69-78.

Lai, Y. (2017). The impact of individual and institutional factors on turnover intent among Taiwanese correctional staff. International Journal of Offender Therapy and Comparative Criminology, 61(1), 100-121. https://doi. org/10.1177/0306624X15589099

Lee, T. W., Burch, T. C., \& Mitchell, T. R. (2014). The story of why we stay: A review of job embeddedness. Annual Review of Organisational Psychology and Organisational Behavior, 1(2014), 199-216. https://doi.org/10.1146/annurevorgpsych-031413-091244

Lyria, R. K., Namusonge, G. S., \& Karanja, K. (2017). The effect of talent retention on organizational performance of firms listed in the Nairobi Securities Exchange. Journal of Human Resource and Leadership, 1(3), 56-68.

Ma, Q. K., Mayfield, M., \& Mayfield, J. (2018). Keep them on-board! How organizations can develop employee embeddedness to increase employee retention Development and Learning in Organizations: An International Journal, 32(4), 5-9. https://doi.org/10.1108/DLO-11-2017-0094

Mafukata, A. M., \& Mudau, A. V. 2016. Exploring teacher mass resignation and early retirement from public schools. Dirasat: Human and Social Sciences, 43(5), 2243-2255.

Mampane, P. M. (2012). The teacher turnover crisis: Evidence from South Africa. Business Education \& Accreditation, 4(2), 73-83.

Marasi, S., Cox, S. S., \& Bennett, R. J. (2016). Job embeddedness: Is it always good thing? Journal of Managerial Psychology, 31(1), 141-153. https://doi. org/10.1108/JMP-05-2013-0150

Mitchell, T. R., Holtom, B. C., Lee, T. W., Sablynski, C., \& Erez, M. (2001). Why people stay: Using job embeddedness to predict voluntary turnover. Academy of Management Journal, 44(2001), 1102-1121. https://doi.org/10.1016/S0191 3085(01)23006-8

Mitchell, T. R., \& Lee, T. W. (2001). The unfolding model of voluntary turnover and job embeddedness: Foundations for a comprehensive theory of attachment. Research in Organisational Behavior, 23(2001), 189-246.
Mitonga-Monga, J., \& Cilliers, F. (2015). Ethics culture and ethics climate in relation to employee engagement in a developing country setting. Journal of Psychology in Africa, 25(3), 242-249. https://doi.org/10.1080/14330237.2015.1065059

Mohammad, A. (2015). Employee recruitment, selection and retention in Saudi Arabian family owned Small and Medium Scale Enterprises (SMEs). Kuwait Chapter of Arabian Journal of Business and Management Review, 4(6), 30-45. https://doi.org/10.12816/0018967

Muhoho, J. M. E. (2014). Assessment of factors influencing employee retention in Tanzania's work organisations. International Journal of Innovation and Applied Studies, 9(2), 687-697.

Naidoo, V., Abarantyne, I., \& Rugimbana, R. (2019). The impact of psychological contracts on employee engagement at a university of technology. SA Journal of Human Resource Management, 17(0), a1039. https://doi.org/10.4102/sajhrm. v17i0.1039

Pearsall, W. (2016). Employees' experiences of recruitment and retention in a research unit located in a rural setting (Unpublished master's dissertation). Pretoria: University of South Africa.

Pek-Greer, P., \& Wallace, M. (2017). A study of childcare teacher retention in the childcare service industry. Global Business Review, 18(1), 1-16. https://doi org/10.1177/0972150916666879

Peltokorpi, V., Allen, D. G., \& Froese, F. (2015). Organizational embeddedness, turnover intentions, and voluntary turnover: The moderating effects of employee demographic characteristics and value orientations. Journal of Organizational Behavior, 36(2015), 292-312. https://doi.org/10.1002/job.1981

Potgieter, I. L., \& Ferreira, N. (2018). Female human resource professionals' job embeddedness in relation to commitment foci: An exploratory study ActaCommercii, 18(1), 1-8. https://doi.org/10.4102/ac.v18i1.493

Roy, B. (2015). A study on employee retention factors in the Indian banking industry An empirical study. International Journal of Advanced Research in Computer Science and Management Studies, 3(3), 346-352.

Ruvimbo, T. S., \& Hlanganipai, N. (2016). Organisational commitment and job retention among nurses in a South African setting: An exploratory study. Journal
of Psychology in Africa, 26(1), 74-77. https://doi.org/10.1080/14330237.2015.1 101283

Sanders, J. W. (2015). The relationships among leader-member exchange, off-the-job embeddedness, and turnover intention (Unpublished doctoral thesis). Scottsdale, AZ: Northcentral University.

Shibiti, R. (2017). The relationship between retention factors, job embeddedness and work engagement of teachers in Tshwane Municipality public schools (Unpublished master's dissertation). Pretoria: University of South Africa.

Takawira, N., Coetzee, M., \& Schreuder, D. (2014). Job embeddedness, work engagement and turnover intention of staff in a higher education institution: An exploratory study. SA Journal of Human Resource Management, 12(1), 1-10. https://doi.org/10.4102/sajhrm.v12i1.524

Thakur, S. J., \& Bhatnagar, J. (2017). Mediator analysis of job embeddedness: Relationship between work-life balance practices and turnover intentions. Employee Relations, 39(5), 718-731. https://doi.org/10.1108/ER-11-20160223

The Centre for Development and Enterprise. (2015). Teachers in South Africa: Supply and demand 2013-2025. Executive summary. Johannesburg: The Centre for Development and Enterprise.

Tourangeau, A. E., Patterson, E., Saari, M., Thomson, H., \& Cranley, L. (2017) Work-related factors influencing home care nurse intent to remain employed. Health Care Management Review, 42(1), 87-97. https://doi.org/10.1097/ HMR.0000000000000093

Tredoux, C., \& Durrheim, K. (2013). Numbers, hypotheses, and conclusions (2nd edn.). Cape Town: UCT Press.

Van Dyk, J., \& Coetzee, M. (2012). Retention factors in relation to organisational commitment in medical and information technology services. SA Journal of Human Resource Management, 8(2), 1-11. https://doi.org/10.4102/sajhrm v10i2.433

Van Dyk, J., Coetzee, M., \& Takawira, N. (2013). Satisfaction with retention factors as predictors of the job embeddedness of medical and information technology services staff. Southern African Business Review, 17(1), 57-75. 